\title{
Data Mining Techniques for IoT enabled Smart Parking Environment : Survey
}

\author{
Anchal $^{1}$, Pooja Mittal ${ }^{2}$ \\ Research Scholar ${ }^{1}$, DCSA, Maharshi Dayanand University, Rohtak, India \\ aanchaldahiyaa@gmail.com \\ Assistant Professor ${ }^{2}$. DCSA, Maharshi Dayanand University, Rohtak, INDIA, mpoojamdu@ gmail.com
}

\begin{abstract}
Recently smart cities have become popular due to the idea of Internet of Things (IoT). IoT is a new technique with the help of which user can connect to various smart devices and sensors to collect real stream data from the system environment. Smart parking environment is one of the current researches as in urban areas millions of vehicles for transportation is used by people in their day to day life for their convenience. Traffic congestion is common problem faced by the users; most of the time people spend their precise time on searching parking slots to park their vehicles. To avoid such types of problem IoT enabled smart parking system become the need of an hour. To collect real stream data with the help of sensors and to filter it using data mining techniques will help to propose the IoT enabled smart parking system. The purpose of this paper is to survey existing smart parking system to find the gaps in existing systems and to discuss various data mining techniques that will help in proposed architecture and can be used to process huge amount of IoT data.
\end{abstract}

Key words: Internet of things (IoT), Knowledge discovery in database (KDD), Radio frequency identification (RFID), Global Positioning system (GPS), Smart environment, Smart Parking, Sensors.

\section{INTRODUCTION}

The rapid growth of information and communication technologies offers opportunities to many societal services, providing users with techniques to access different types of systems. Study provides different data mining techniques that can be used to implement IoT enabled smart parking environment. In the domain of smart parking systems, over the last twenty years different technologies have emerged. Increasing traffic leads to fuel consumption increased, and also increase pollution and driving time along with unwanted traffic jams and accidents [12]. IoT enabled smart parking system provides an environment that will help to alert the drivers where the free parking space is available [46]. Data mining is one of the alternate that makes IoT smarter by analysis of data. Data mining is a technique that analyses large databases that will automatically process the hidden pattern which are legitimate, unconventional, functional and coherent [15]. Knowledge discovery in database (KDD) is another term that is used for data mining [8]. Data mining overlaps with other domains like machine leaning, statistics, databases, artificial intelligence (AI). It is mainly focused on automatic handling of algorithms and large heterogeneous data. The purpose of the paper is to make a review of IoT enabled smart parking system that is accessible to the drivers so that they will get information about the free parking slots available for parking. By this way and with sensors, actuators and $\mathrm{HD}$ cameras every driver who have facing problem of free parking slots can be monitored and the data and video can be transferred through the internet and the saved information to the cloud about the free parking slot is passed to the driver so they can be guided on time about the available parking slot in the near place.

\section{RELATED WORK}

The metropolitan areas are getting more congested and populated. To manage the parking places is becoming the issue for the system. An efficient smart parking system becomes the need for people by 
minimizing the time to find a parking place and to optimize parking space utilization rate.

The demand of free parking space is a dynamic value i.e. a value that changes over time. For providing the real time information we will use "A Guided Parking System"[34]. By using this system the possibility to improve the process of parking and efficiency is increased. Guided Parking system (GPS) have 4 fragments i.e monitor parking slots, information diffusion, communication technology and the control system [35]. To monitor the occupied slots GPS system either use smart sensors or cameras. For the purpose of tracking sensors based system is further divided as "On-Roadway" or "Off-Roadway". The "On-road" sensors are also called as magnetic sensors that are attached to the surface of roads. The off road sensors are called as smart cameras for monitoring that are placed above road surface.

Recently "crowd sourcing" is more advanced technique that is used for detecting the parking lot and tracking the vehicles [36]. To detect the free spaces near the parked vehicles ultra sonic range finders are placed in each vehicle that will collect the information. The information is diffused to the other users that will help to find the free parking slots.

"Photoelectric sensors" is another technique that detects the vehicles in restricted region. At the entry and the exit point of the parking "sensors" are installed that are connected with the server that processes the information about the vehicles. Real time information is provided by such type of display and also provides information about number of parking slots and we can connect it with the IoT enabled parking system to get the more accurate results.

"Drones" are used for processing the images that are used for smart transportation [37]. The work presented using drones use "drone cameras" that will detain the videos and evaluate it for free parking place and jamming on the roads. Processing the images using drones don't provide the reliable result to the user because numbers of times weather condition is not suitable for drones.
Optimal resource allocation and reservation is a technique that is based on the principle of distance between the driver and the parking slot. This technique uses Mixed Integer Linear Program (MILP) that solves the problem in time driven sequence. Each MILP gives an optimal allocation that is based user current information and also supports random events such as a new user request, parking availability etc. The allocation is updated at the next decision point which ensures that there is no parking slot reservation conflict and none of the user is never assigned a parking slot [35] .

Another technique used for smart parking system is ZigBee. ZigBee technique uses a network the sends the user requested information to the PC through a coordinator and also update the database. Using internet updated information is provided to the user of the application. This information is used by the drivers that will help them to find the free parking slot in the congestion. With the help of this technique real time information is easily available to the drivers. Table 1 represents different findings and gaps exits in the current parking systems. This table helps us to make a comparative analysis of the different techniques that will help us to analyze the systems. 


\begin{tabular}{|c|c|c|c|c|}
\hline Paper Name & Aim & Methodology & Findings & Gaps \\
\hline $\begin{array}{l}\text { "Real - Time } \\
\text { Smart Parking } \\
\text { System } \\
\text { Integration in } \\
\text { Distributed ITS } \\
\text { for Smart Cities" } \\
\text { [39] }\end{array}$ & $\begin{array}{l}\text { Smart } \\
\text { implementation of } \\
\text { Parking System. }\end{array}$ & $\begin{array}{l}\text { Decision Tress, } \\
\text { Logistic } \\
\text { Regression. }\end{array}$ & $\begin{array}{l}\text { Datasets can easily } \\
\text { be created with the } \\
\text { help of RFID and } \\
\text { sensors which can } \\
\text { help to sense real } \\
\text { stream data. }\end{array}$ & $\begin{array}{l}\text { Weather condition may } \\
\text { affect the visibility of } \\
\text { the parking. }\end{array}$ \\
\hline $\begin{array}{l}\text { "A Prototype for } \\
\text { IoT based car } \\
\text { Parking } \\
\text { management } \\
\text { system for smart } \\
\text { cities" [40] }\end{array}$ & $\begin{array}{l}\text { To transfer seamless } \\
\text { real stream data } \\
\text { using data mining } \\
\text { techniques in IoT } \\
\text { enabled } \\
\text { environment. }\end{array}$ & $\begin{array}{l}\text { Neural Networks, } \\
\text { Regression Tree. }\end{array}$ & $\begin{array}{l}\text { Cost reduction, } \\
\text { increase reliability, } \\
\text { help in prediction of } \\
\text { slots in near area. }\end{array}$ & $\begin{array}{l}\text { Not possible to collect } \\
\text { the real time data in } \\
\text { cloudy days. }\end{array}$ \\
\hline $\begin{array}{l}\text { "Parking } \\
\text { Availability } \\
\text { Prediction for } \\
\text { Sensor-Enabled } \\
\text { Car Parks in } \\
\text { Smart Cities" } \\
\text { [41] }\end{array}$ & $\begin{array}{l}\text { To self schedule } \\
\text { maintains and } \\
\text { sharing of free and } \\
\text { occupied slots to the } \\
\text { user. }\end{array}$ & $\begin{array}{l}\text { Classification, } \\
\text { Support Vector } \\
\text { Regression. }\end{array}$ & $\begin{array}{l}\text { Cost effective, } \\
\text { energy and time } \\
\text { saver for the users. }\end{array}$ & $\begin{array}{l}\text { Problem in determining } \\
\text { the fixed schedule. }\end{array}$ \\
\hline $\begin{array}{l}\text { "Wireless } \\
\text { Sensor network } \\
\text { and RFID for } \\
\text { smart parking } \\
\text { system" [42] }\end{array}$ & $\begin{array}{l}\text { Different Processes } \\
\text { that are helpful for } \\
\text { traffic management } \\
\text { using data mining. }\end{array}$ & $\begin{array}{l}\text { Data collection, } \\
\text { Data cleaning, and } \\
\text { problem } \\
\text { formulation. }\end{array}$ & $\begin{array}{l}\text { Different sources are } \\
\text { available through } \\
\text { which we can collect } \\
\text { real time data. }\end{array}$ & $\begin{array}{l}\text { Anomalies are present } \\
\text { in current system like } \\
\text { sensors don't work } \\
\text { properly. }\end{array}$ \\
\hline $\begin{array}{ll}\text { "Novel } & \text { IoT } \\
\text { Access } & \\
\text { architecture for } \\
\text { vehicle } & \\
\text { monitoring } & \\
\text { system"[43] } & \end{array}$ & $\begin{array}{lr}\text { Vehicle monitoring } \\
\text { using r Field } \\
\text { Programming } \quad \text { Gate } \\
\text { Array (FPGA). }\end{array}$ & $\begin{array}{l}\text { FPGA } \\
\text { methodology is } \\
\text { used "which can } \\
\text { provide a unified } \\
\text { access to the IoT } \\
\text { for a wide variety } \\
\text { of low speed and } \\
\text { high speed } \\
\text { devices". }\end{array}$ & $\begin{array}{l}\text { "Photoelectric } \\
\text { sensors" to identify } \\
\text { the vehicles in a } \\
\text { restricted and real } \\
\text { time system are } \\
\text { possible. }\end{array}$ & $\begin{array}{l}\text { How efficiently choose } \\
\text { parking slot in less time } \\
\text { is not properly } \\
\text { designed. }\end{array}$ \\
\hline $\begin{array}{l}\text { "A cloud based } \\
\text { intelligent car } \\
\text { parking services } \\
\text { for } \quad \text { smart } \\
\text { cities"[44] }\end{array}$ & $\begin{array}{l}\text { To make a sensor } \\
\text { network that will } \\
\text { reduce the gap } \\
\text { between the user } \\
\text { and the IoT enabled } \\
\text { smart parking. }\end{array}$ & $\begin{array}{l}\text { Classification, } \\
\text { Neural Networks. }\end{array}$ & $\begin{array}{l}\text { Scalability, } \\
\text { Interoperability, } \\
\text { efficiency of data. }\end{array}$ & $\begin{array}{l}\text { If system is hacked } \\
\text { then user may faced } \\
\text { different types of } \\
\text { consequences. }\end{array}$ \\
\hline $\begin{array}{l}\text { "Car park } \\
\text { management } \\
\text { with networked } \\
\text { wireless sensors } \\
\& \text { active RFID" } \\
{[45]}\end{array}$ & $\begin{array}{l}\text { To improve the } \\
\text { process of parking } \\
\text { and improve the } \\
\text { efficiency. }\end{array}$ & $\begin{array}{l}\text { Guided Parking } \\
\text { system is used. }\end{array}$ & $\begin{array}{l}\text { Architecture is fully } \\
\text { automated. }\end{array}$ & $\begin{array}{lr}\text { Complex } & \text { design, } \\
\text { Multilevel parking } & \text { pystem is not defined. }\end{array}$ \\
\hline
\end{tabular}

Table 1: Comparative analysis of different techniques used for smart parking system with existing gaps and findings 
In comparative analysis table we study different research papers and saw how technological advancement in the field of smart parking system has been take place. To search the free parking space in urban area is becoming issue in day to day life. We survey different techniques like GPS [34], crowd sourcing technique [36] that is based on ultra sonic range finder that detects free places near parked vehicles. Drones are also used in smart parking system that capture the videos and then analyze the free space. Smart parking system survey based on internet of things have numbers of gaps such as security related problem in existing system, difficult to collect real stream data, difficult to collect data on rainy days, difficulty in data fusion and filtering etc. Future research will be based on gaps present on the existing system that will help to implement the new IoT enabled smart parking system that will help the user to find free parking slots in less time.

\section{UTILITY IN SMART ENVIRONMENT}

Smart environment that is based on internet of things consist smart cities, smart utility, smart homes, smart parking system etc. If we are talking about smart environment then everything must be connected to the internet to make it smarter. For example IoT helps to monitor the traffic congestion in urban cities with the help of sensing capabilities and the "GPS" installed in smart vehicles [20]. It further helps in smart parking system that is based on "road sensors" and "intelligent displays" that monitors the best path for parking in smart cities. For making the environment smart we can use data mining techniques that will help to collect real stream data from different application and on the basis of data collected from different sources we can implement the environment i.e. smart parking system that will guide the users about the free parking slot available in nearest place. Table 2 represents some applications of data mining and popular functionalities.

\begin{tabular}{|c|c|c|c|}
\hline Area & $\begin{array}{l}\text { Classifi } \\
\text { cation }\end{array}$ & Clustering & $\begin{array}{l}\text { Association } \\
\text { Analysis }\end{array}$ \\
\hline $\begin{array}{l}\text { Smart } \\
\text { Parking }\end{array}$ & Yes & Yes & Yes \\
\hline $\begin{array}{l}\text { Smart } \\
\text { city }\end{array}$ & Yes & Yes & No \\
\hline $\begin{array}{l}\text { Health } \\
\text { care }\end{array}$ & Yes & Yes & No \\
\hline $\begin{array}{l}\text { E- } \\
\text { commerce }\end{array}$ & No & Yes & No \\
\hline $\begin{array}{l}\text { Smart } \\
\text { Home }\end{array}$ & Yes & Yes & Yes \\
\hline $\begin{array}{l}\text { City } \\
\text { Governan } \\
\text { ce }\end{array}$ & Yes & Yes & Yes \\
\hline
\end{tabular}

Table 2: "Applications of Data mining and most popular mining functionalities"

The table summarizes different application areas where we can use data mining techniques. Using one of the given techniques we can implement IoT enabled Smart parking system in future. In next section we will discuss about different mining techniques that will help to implement smart parking system.

\section{DATA MINING TECHNIQUES}

To implement the IoT enabled smart parking system following data mining techniques can be used i.e "classification", "clustering", "association analysis", "time series analysis" and "outlier analysis". These techniques help us to understand the different uses of the mining techniques that will help us to solve our problem. The Figure 1 depicts the different data mining techniques that are used in different application area such as healthcare, education, market basket analysis, fraud detection, parking system, intrusion detection, security, etc. Brief explanation of some mining techniques is given below. 


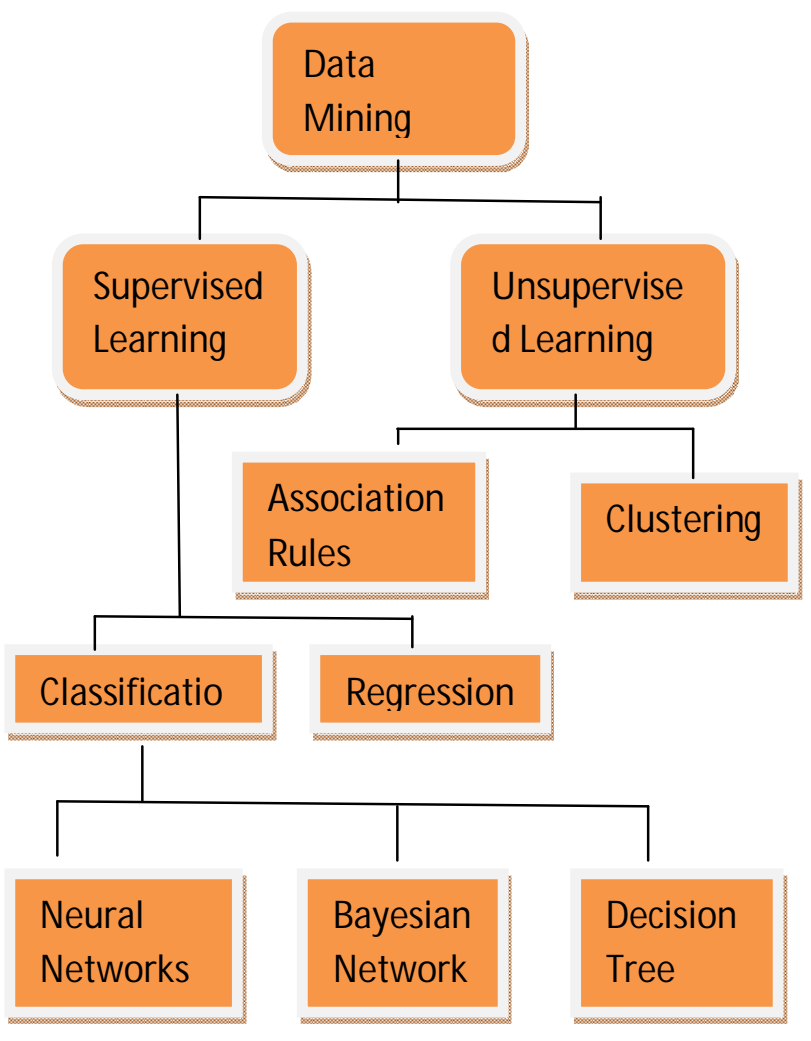

Figure 1: Classification of Data Mining Techniques

\subsection{Supervised Learning}

"It is data mining task of inferring function from labeled training data". A supervised learning algorithm analyzes the training data and produces the inferred function, which can be used for mapping new examples.

\subsection{Unsupervised Learning}

It is data mining task which try to find hidden structure in unlabeled data." There is no error or reward signal to evaluate a potential solution". Let's take an example of different kinds of vehicles and the task is to arrange them as groups. We have four types of vehicles like activa, car, auto and truck. Table 3 represents an example of supervised and unsupervised learning that will help us to understand the concept of supervised and unsupervised learning.

\begin{tabular}{|c|c|c|c|c|}
\hline $\begin{array}{l}\text { Item } \\
\text { No. }\end{array}$ & Category & Size & Feature & $\begin{array}{l}\text { vehicle } \\
\text { Name }\end{array}$ \\
\hline 1 & $\begin{array}{l}\text { Two } \\
\text { wheeler }\end{array}$ & Small & $\begin{array}{l}\text { Drum } \\
\text { Brakes, } \\
\text { Sheet } \\
\text { Metal } \\
\text { Wheels }\end{array}$ & Activa \\
\hline 2 & $\begin{array}{l}\text { Three } \\
\text { wheeler }\end{array}$ & Small & $\begin{array}{l}\text { 4- stroke } \\
\text { engine, } \\
\text { compact } \\
\text { design }\end{array}$ & Auto \\
\hline 3 & $\begin{array}{l}\text { Four } \\
\text { wheeler }\end{array}$ & Big & $\begin{array}{l}\text { Antilock } \\
\text { breaking } \\
\text { system, } \\
\text { Airbags, } \\
\text { Rear } \\
\text { parking } \\
\text { sensors. }\end{array}$ & Car \\
\hline 4 & $\begin{array}{l}\text { Eight } \\
\text { wheeler }\end{array}$ & Big & $\begin{array}{l}\text { Power } \\
\text { steering, } \\
\text { Heavy } \\
\text { duty Rear } \\
\text { suspensio } \\
\text { n }\end{array}$ & Truck \\
\hline
\end{tabular}

Table 2: Represents an example for supervised leaning and unsupervised Learning

Let's take a vehicle from the list then see the category, size and feature of the particular vehicle. If category is 2-wheeler, size is small, and feature is drum brake we will infer the vehicle name as activa and put in 2 wheeler group. Here we observe in the above table that a column was labeled as "vehicle Name" is called the response variable. If we learn the thing before training data and then apply the knowledge to the test data (for new vehicle) this type of learning is called supervised leaning [38]. In unsupervised leaning we don't have any knowledge about the vehicles so how we will arrange them. Suppose we take vehicle and arrange them by considering physical character of that particular vehicle like size. We will arrange according to the base condition i.e size. Small size group: activa and auto; Category group 2-wheeler and 3-wheeler and so on. Here we did not learn anything before, it mean no train data and no response variable. This type of learning is called unsupervised learning.

\subsection{Classification}

It is a technique in which we can categorize the data into a given number of classes. The main aim of this technique is to find the class that is similar to the 
categorize data. It can be performed both on structured and unstructured data. Classification is important for the decision making management. Steps involved in classification technique are initialized the classifier, train the classifier, predict the target. Accurately predict the target class is the main goal of the classification. Number of methods are there that classify the data, including decision tree induction, rule-based expert systems, hierarchical classification, neural networks, support vector machines etc.

\subsection{Clustering}

It divides the data into meaningful groups. Here meaningful group's means that pattern in the same set are related in some sense and patterns in different groups are dissimilar in the some sense [25]. Searching for clusters involves unsupervised learning [25]. Without consulting a known class model unsupervised learning technique analyzes the data object. Different methods are used for the purpose clustering such as Hierarchical method, partitioning method etc.

\subsection{Association Analysis}

It uses market basket analysis. It is useful for discovering compelling relationships in large datasets. "The uncovered relationships can be represented in the form of association rules that can be helpful in generation of more qualitative knowledge which helps in decision making". In future we will implement smart parking system using one of the data mining techniques. In next section we will discuss about IoT enabled Smart parking architecture using data mining techniques.

\section{INTEGRATED IOT ENABLED SMART PARKING ARCHITECTURE USING DATA MINING}

Increase in city traffic requires to availability of free space for parking. Finding a free parking lot during rush hours is real trouble. The parking availability is censored in real- time that technology opens up a chance for the provision of smart parking solutions that assist advance parking lot booking and dynamic pricing [16]. "The Internet of Things is a new communication model, in which the things of everyday life will be supplied with microcontrollers, transceivers for digital communication, and protocol stacks that will make them able to interact with each other and becoming an integral part of the internet "[16]. Intelligent transportation system is one of the important applications of the IoT. To compare with the traditional parking lots intelligent parking lots can provide better service experience through the multisensor information fusion technology. As we know that sensors and RFID technology is used to collect data from different sources [20]. Bulk of data is generated by sensors to handle large amount of data we will use data mining techniques that will help to process the large amount of data and provide the processed information to the user. IoT Enabled data mining architecture for smart parking system includes the following steps:

5.1 Devices: Data generated every time is collected continuously by the integration of number of IoT devices such as cameras, sensors, RFID and other devices into the system. For the collection of continuously data generated we can use different tools that are available in the market At device layer of smart parking architecture we can use cameras, RFID, sensors that will collect data from different sources.

5.2 Raw Data: Structured, unstructured, and semistructured data can be integrated in data mining system. Data mining processes raw data into useful information. For processing raw data; data mining apply different cleaning approaches so that we can remove noisy data. Techniques that are mostly used to handle noisy data are binning method, regression, clustering etc.

5.3 Data gather: Data can be collected from real stream data and batch data. All data should be parsed after that we can analyze it, merged and store into data warehouses. Before storing the data into data warehouse sometimes we need to transform that data. Data transformation operation makes the data useful for the mining process. It includes the following steps Smoothing, aggregation, generalization, normalization 
Service Layer

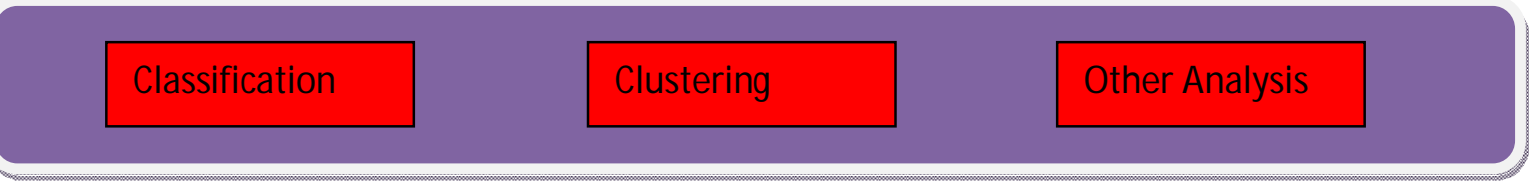

Data Processing Layer

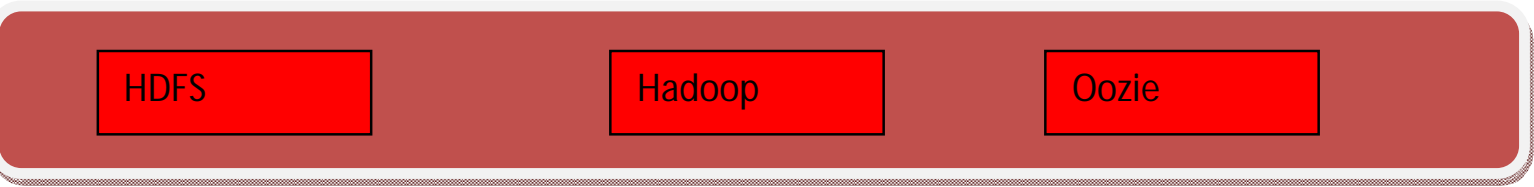

Data Gather Layer

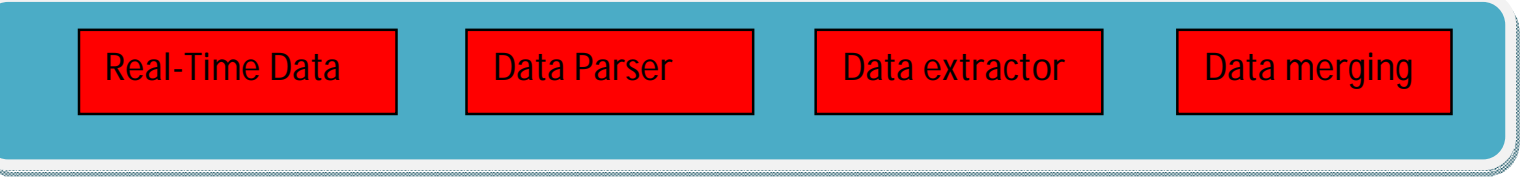

Raw Data Layer

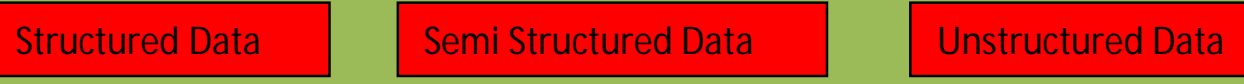

Device Laver

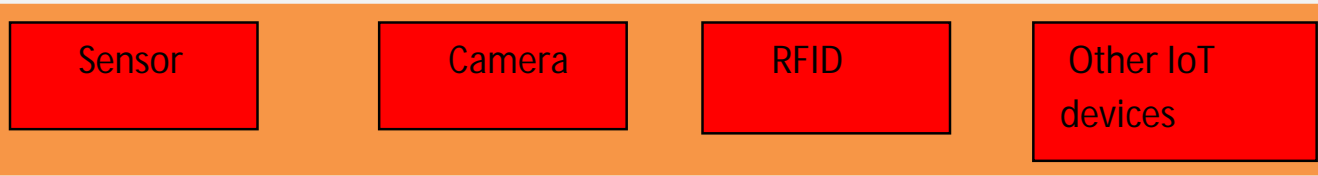

Figure 2: Suggested IoT Enabled Data Mining Architecture [39]

5.4 Data Processing: Hadoop, HDFS, and Oozie are the open sources that can be integrated for the processing of data. "Hadoop" is an open source software utility that manages processing of data and storage for big data applications running in cluster system [38]. It supports predictive analytics, data mining and machine learning applications. Security is important to data mining system. It protects the data from unauthorized access and privacy disclosure.

5.5 Services: Data mining functionality will be provided as service. The suggested IoT enabled Data mining architecture depicts in bottom up manner i.e. below layer is for devices that consist of sensors, cameras, and other IoT devices that will help to collect data from real time applications and so on. Fig. 2 depicts the diagrammatic representation of IoT enabled data mining architecture.

For implementing the suggested IoT Enabled mining architecture we have to follow the data mining process that will include the following steps: Data Analysis and Preparation for Parking: This step helps to prepare the data for mining. It includes $3 \mathrm{sub}$ steps: integrate data from various parking lots and clean the noise from that data; extract information about free parking lots available from these integrated sources; preprocess the data to facilitate data mining. Preprocessing means that after extracting data from different sources to we need to apply the cleaning process. It includes missing data, noisy data etc. 
Data Mining and Evaluation: We can apply different mining algorithms to find the hidden patterns and according to them make an evaluation of discovered edge. Data Presentation: It refers to visualization of data and represents mined knowledge i.e. free parking lots to the users. Future plan is the implementation of IoT enabled smart parking system that will help the user to find free parking slots in less time and this will help to reduce the traffic congestion in the city. In next section we will conclude the survey paper.

\section{CONCLUSION}

The need of smart parking system arises due to traffic congestion in metropolitan areas where people use transportation for their convenience. To make smart decision both for human beings and for the things in the IoT, data mining techniques are integrated with IoT techniques for decision support and optimizing the system. We survey existing smart parking system that have number of gaps such as how to process received data from the parking sensors that includes " filtering" and "data fusion" . How to conduct "data filtering and data fusion" are still open challenges. In this paper we review different data mining techniques that provide useful patterns to the IoT enabled smart parking system and make a comparative analysis of the techniques that were used. Also propose architecture that will help to implement the smart parking system. In future we can implement these techniques in proposed architecture to make the IoT enabled smart parking system.

\section{REFERENCES}

[1] L. Atzori, A. Iera, and G. Morabito, "The internet of things: A survey," Comput. Netw., vol. 54, no. 15, pp. 2787-2805, 2010.

https://doi.org/10.1016/j.comnet.2010.05.010

[2] H. Schaffers, N. Komninos, M. Pallot, B. Trousse, M. Nilsson, and A. Oliveira, "Smart cities and the future internet: Towards cooperation frameworks for open innovation, "The Future Internet, Lect. Notes Computer Sci., vol. 6656, pp. 431-446, 2011.

https://doi.org/10.1007/978-3-642-20898-0_31

[3] Tsai, Chun-Wei, et al. "Data mining for internet of things: A survey. "Communication survey \& Tutorials, IEEE 16.1(2014):77-97. https://doi.org/10.1109/SURV.2013.103013.00206 [4] C.-W. Tsai, C.-F. Lai, and A. V. Vasilakos, "Future internet of things: open issues and challenges, "Wireless Networks, vol. 20 no. 8, pp. 2201-2217, 2014.

https://doi.org/10.1007/s11276-014-0731-0

[5] H. Jiawei and M. Kamber, Data Mining: Concepts and Techniques, Morgan Kaufmann, 2011

[6] A. Mukhopadhyay, U. Maulik, S. Bandyopadhyay, and C. A.C. Coello, "A survey of multiobjective evolutionary algorithms for data mining: part I," IEEE Transactions on Evolutionary Computation, vol. 18, no. 1, pp. 4-19, 2014.

[7] Y. Zhang, M. Chen, S. Mao, L. Hu, and V. Leung, "CAP: crowd activity prediction based on big data analysis," IEEE Network, vol. 28, no. 4, pp. 52-57, 2014.

[8] M. Chen, S. Mao, and Y. Liu, "Big data: a survey," Mobile Networks and Applications, vol. 19, no. 2, pp. 171-209, 2014.

[9] M. Chen, S. Mao, Y. Zhang, and V. Leung, Big Data: Related Technologies, Challenges and Future Prospects, SpringerBriefs in Computer Science, Springer, 2014.

[10] Muhammad Alam, David Moroni, Gabriele Pieri, Marco Tampucci: Real-Time Smart Parking System Integration in Distributed ITS for Smart Cities.2018.

https://doi.org/10.1155/2018/3437278

[11] J. Wan, D. Zhang, Y. Sun, K. Lin, C. Zou, and H. Cai, "VCMIA: a novel architecture for integrating vehicular cyber-physica lsystems and mobile cloud computing," Mobile Networks and Applications, vol. 19, no. 2, pp. 153-160, 2014.

[12] X. H. Rong, F.Chen, P. Deng, and S. L.Ma, "Alarge-scale device collaboration mechanism," Journal of Computer Research and Development, vol. 48, no. 9, pp. 1589-1596, 2011.

[13] F. Chen, X.-H. Rong, P. Deng, and S.-L.Ma, "A survey of device collaboration technology and system software," Acta Electronica Sinica, vol. 39, no. 2, pp. 440-447, 2011.

[14] L. Zhou, M. Chen, B. Zheng, and J. Cui, "Green multimedia communications over Internet of Things," in Proceedings of the IEEE International Conference on Communications (ICC'12), pp.19481952, Ottawa, Canada, June 2012.

[15] Yanxu Zheng, Sutharshan Rajasegarar, Christopher Leckie: Parking Availability Prediction for Sensor -Enabled Car Parks in Smart Cities, IEEE, international conference on Intelligent Sensors, 2015.

[16]J. Wan, D. Zhang, Y. Sun, K. Lin, C. Zou, and H. Cai, "VCMIA: a novel architecture for integrating vehicular cyber-physica lsystems and mobile cloud computing," Mobile Networks and Applications, vol. 19, no. 2, pp. 153-160, 2014.

https://doi.org/10.1007/s11036-014-0499-6

[17] X. H. Rong, F.Chen, P. Deng, and S. L.Ma, "Alarge-scale device collaboration mechanism ] A. Mukhopadhyay, U. Maulik, S. Bandyopadhyay, and C. A.C. Coello, "A survey of multiobjective 
evolutionary algorithms for data mining: part I," IEEE Transactions on Evolutionary Computation, vol. 18, no. 1, pp. 4-19, 2014.," Journal of Computer Research and Development, vol. 48, no. 9, pp. 15891596, 2011.

[18] F. Chen, X.-H. Rong, P. Deng, and S.-L.Ma, "A survey of device collaboration technology and system software," Acta Electronica Sinica, vol. 39, no. 2, pp. 440-447, 2011.

[19] L. Zhou, M. Chen, B. Zheng, and J. Cui, "Green multimedia communications over Internet of Things," in Proceedings of the IEEE International Conference on Communications (ICC'12), pp.19481952, Ottawa, Canada, June 2012.

[20]. L. Atzori, A. Lera and G. Morabito, " The Internet of things: a survey," Computer Network , Vol 54, no. 15.

[21] Li, T.S; Ying- Chieh, Y. Jyun-Da; MingYing, H. Chih- Yang, Multifunction intelligent autonomous parking controllers for carlike mobile robots. IEEE Trans. Ind. Electrons. 2010,57,16871700.

[22] Faheem S.A. Mahmud, G.M. Khan, M. Rahman ; A survey of Intelligent Car Parking System; October 2013.

[23] Broll, G., Rukzio, E., Paolucci, M., Wagner, M., Schmidt, A., \& Hussmann, H. (2009). Perci: pervasive service interaction with the internet of things. IEEE Internet Computing, 13(6), 74-81.

[24]A.Mukhopadhyay, U. Maulik, S. Bandyopadhyay, and C. A.C. Coello, "A survey of multiobjective evolutionary algorithms for data mining: part I," IEEE Transactions on Evolutionary Computation, vol. 18, no. 1, pp. 4-19, 2014.

[25] Y. Zhang, M. Chen, S. Mao, L. Hu, and V. Leung, "CAP: crowd activity prediction based on big data analysis," IEEE Network, vol. 28, no. 4, pp. 52-57, 2014.

https://doi.org/10.1109/MNET.2014.6863132

[26] M. Chen, S. Mao, and Y. Liu, "Big data: a survey," Mobile Networks and Applications, vol. 19, no. 2, pp. 171-209, 2014.

[27] M. Chen, S. Mao, Y. Zhang, and V. Leung, Big Data: Related Technologies, Challenges and Future Prospects, SpringerBriefs in Computer Science, Springer, 2014.

[28] X. H. Rong, F.Chen, P. Deng, and S. L.Ma, "Alarge-scale device collaboration mechanism," Journal of Computer Research and Development, vol. 48, no. 9, pp. 1589-1596, 2011.

[29] F. Chen, X.-H. Rong, P. Deng, and S.-L.Ma, "A survey of device collaboration technology and system software," Acta Electronica Sinica, vol. 39, no. 2, pp. 440-447, 2011.

[30] Dada, A., \& Thiess, F. (2008). Sensor applications in the supply chain: the example of quality-based issuing of perishables. LNCS, 4952.
[31] Deng, R. H., Li, Y., Yung, M., \& Zhao, Y. (2010). A new framework for RFID privacy. LNCS, 6345, 1-18.

[32] IERC. (2013). Coordinating and building a broadly based consensus on the ways to realise the internet of things in Europe.

[33] Jara, A. J., Zamora-Izquierdo, M. A., \& Skarmeta, A. F. (2013). Interconnection framework for mHealth and remote monitoring based on the internet of things. IEEE Journal on Selected Areas in Communications, 31(9), 47-65.

[34] M. Kodransky and G.Herman, Europe's Parking U-Turn : From Accommodation to Regulation, Institu for Transportation and Development Policy, 2011, https://www.itdp.org/wpcontent/upload/2014/07/Euro pes-Parking-U-Turn-ITDP. pdf, Accessed on: 15 September, 2017.

[35] V.W.S. Tang, Y. Zheng, and J.Cao,'An intelligent car park management system based on wireless sensor networks," in Proceedings of the SPCA 2006: $1^{\text {st }}$ International Symposium on Pervasive Computing and Applications, pp. 65-70, August 2006.

https://doi.org/10.1109/SPCA.2006.297498

[36] L.Ruizhi, R. Cristian, B. Peter, O.Shumao, and C.Liping, "Crowdsourcing on-street parking space detection," https:// arxiv.org/abs/1603.00441, 2016.

[37] G.Maria, E.Baccaglini, D.Brevi, M.Gavelli, and R. Scopigno, " A drone-based image processing system for car detection in a smart transport infrastructure," in Proceedings of the $18^{\text {th }}$ Mediterranean Electrotechnical Conference, MELECON 2016, pp. 1-5, April 2016.

[38]. www. Google ca/search/source=hp\&ei.

[39] Muhammad Alam, Davide Moroni, Gabriele Pieri, Marco Tampucci,"Real-Time Smart Parking Systems Integration in Distributed ITS for Smart cities" Journal of Advanced Transportation, vol. 13, 2018.

[40] Baratam. M Kumar Gandhi and M. Kameswara Rao. 2016,"A Prototype for IoT based Car Parking Management System for Smart Cities", International Journal of Science \& Technology.

[41] Yanxu Zheng, Sutharshan Rajasegarar, Chistopher Leckie'Parking Availability Prediction for Sensors-Enabled Car Parks in Smart Cities"IEEE , International conference on ISSNIP,2015.

https://doi.org/10.1109/ISSNIP.2015.7106902

[42] Patil, M., \& Bhonge, V. N. 2013, "Wireless sensor network and RFID for smart parking system", International Journal of Emerging Technology and Advanced Engineering.

[43] Shulong Wang, Yibin Hou, Fang Gao “ A Novel IoT Access Architecture for Vehicle Monitoring System” IEEE, 2016.

[44] Z. Ganchev, I. O’ Droma, M. Zhang ," A Cloud based intelligent car parking sevices for smart 
Anchal et al., International Journal of Advanced Trends in Computer Science and Engineering, 8(4), July- August 2019,1688 - 1697

cities," In General Assembly and Scientific Symposium . IEEE ,2014.

[45] ElMouatezbillah Karbab, "Car Park Management with Networked Wireless Sensors and Active RFID ", IEEE.

[46] Deepti Rani, Nasib Singh Gill, “ Lightweight Security Protocol for Internet of Things: A Review," International Journal of Advanced Trends in Computer Science and Engineering, volume 8,2019 .

https://doi.org/10.30534/ijatcse/2019/58832019 